\title{
Live kidney donors with lower pre-donation GFR have poorer renal function after two years
}

\author{
Ahmed-Salim $Y^{*}$, Ibrahimi M*, Kujawiak I*, Trotter P, Hosgood S, Nicholson M \\ School of Clinical Medicine and Department of Surgery, University of Cambridge
}

\section{Background}

-A third of all kidney transplants carried out in the UK are from living donors. Kidneys from live donors have lower rates of delayed graft function and longer term graft survival compared to cadaveric kidneys. -Currently, living donors have a wide range of pre-donation renal function, with guidelines in the UK stratifying acceptable pre donation GFRs according to donor age. ${ }^{1}$

-These GFR thresholds should be set to ensure donors have sufficient kidney function after donation to avoid the risk of developing significant renal impairment.

\section{Aim}

The aim of this study was to determine the relationship between predonation GFR and the residual renal function during follow up.

\section{Patients and Methods}

-We performed a retrospective analysis of a series of 222 living kidney donors who underwent laparoscopic live donor nephrectomy in Addenbrooke's Hospital, Cambridge, between January 2011 and July 2016.

-Data was obtained from internal electronic records, paper records and requested from NHS Blood and Transplant.

-Mean $( \pm S D)$ age at donation was $51 \pm 11$ years and the male to female ratio was $1: 1.13$.

-Statistical analysis was performed using GraphPad Prism software.

\section{Results}

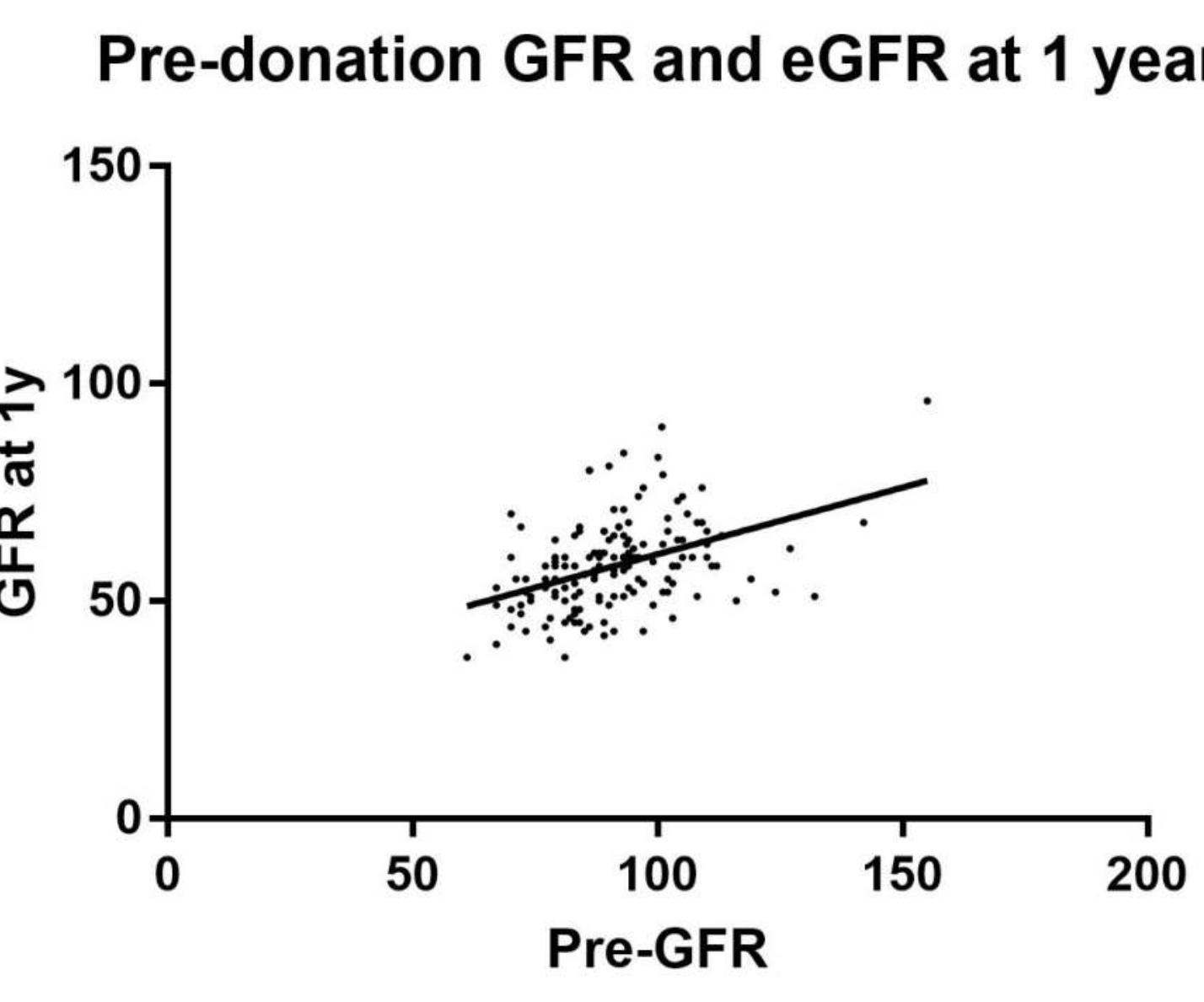

Calculated GFR prior to donation positively correlated with estimated GFR 1 year after donation $p=<0.0001^{* * * *}, r=0.4315$

Pre-donation GFR and eGFR at 2 years

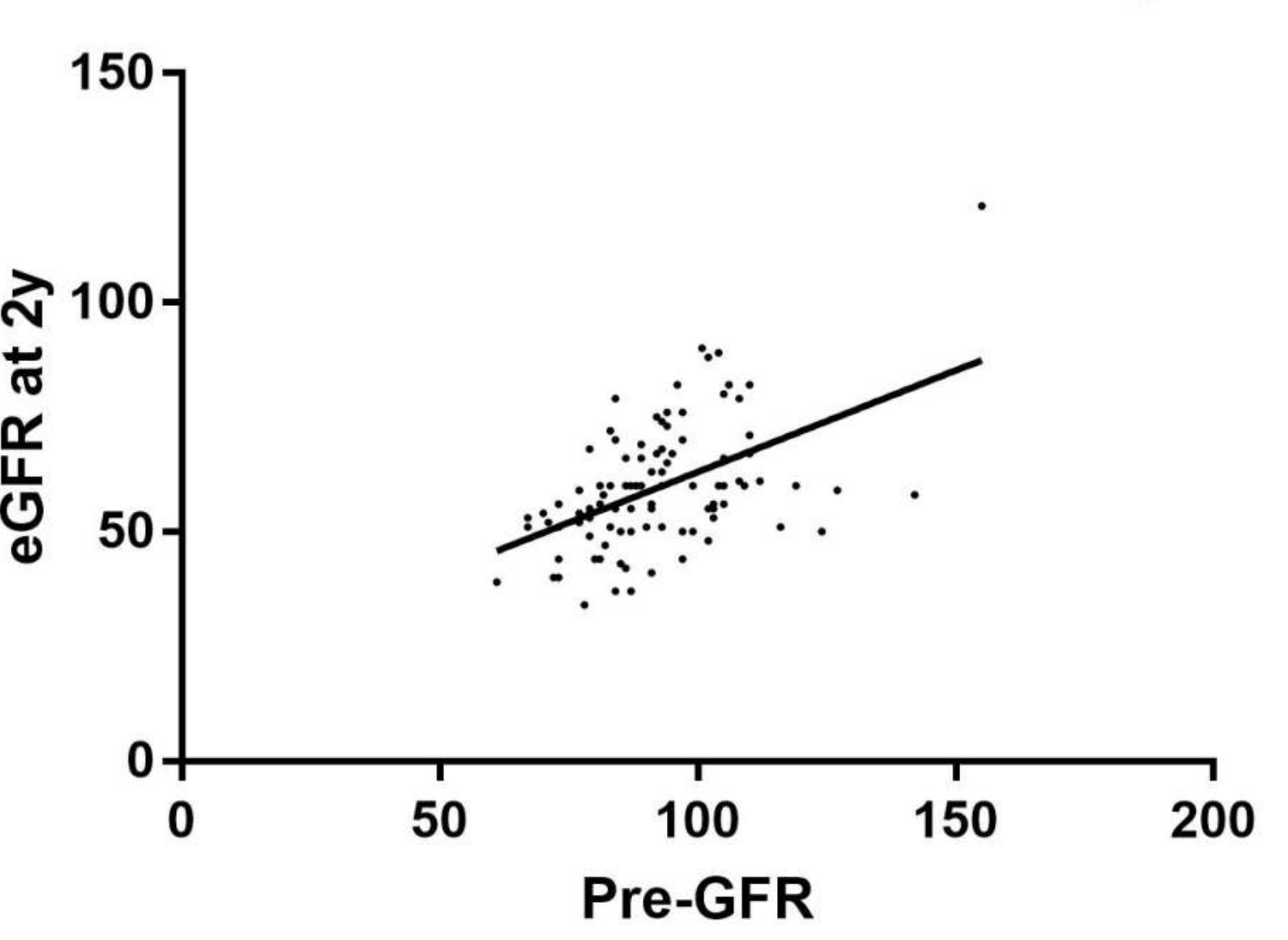

Calculated GFR prior to donation positively correlated with estimated GFR 2 years after donation, $p=<0.0001^{* * * *} R=0.4711$

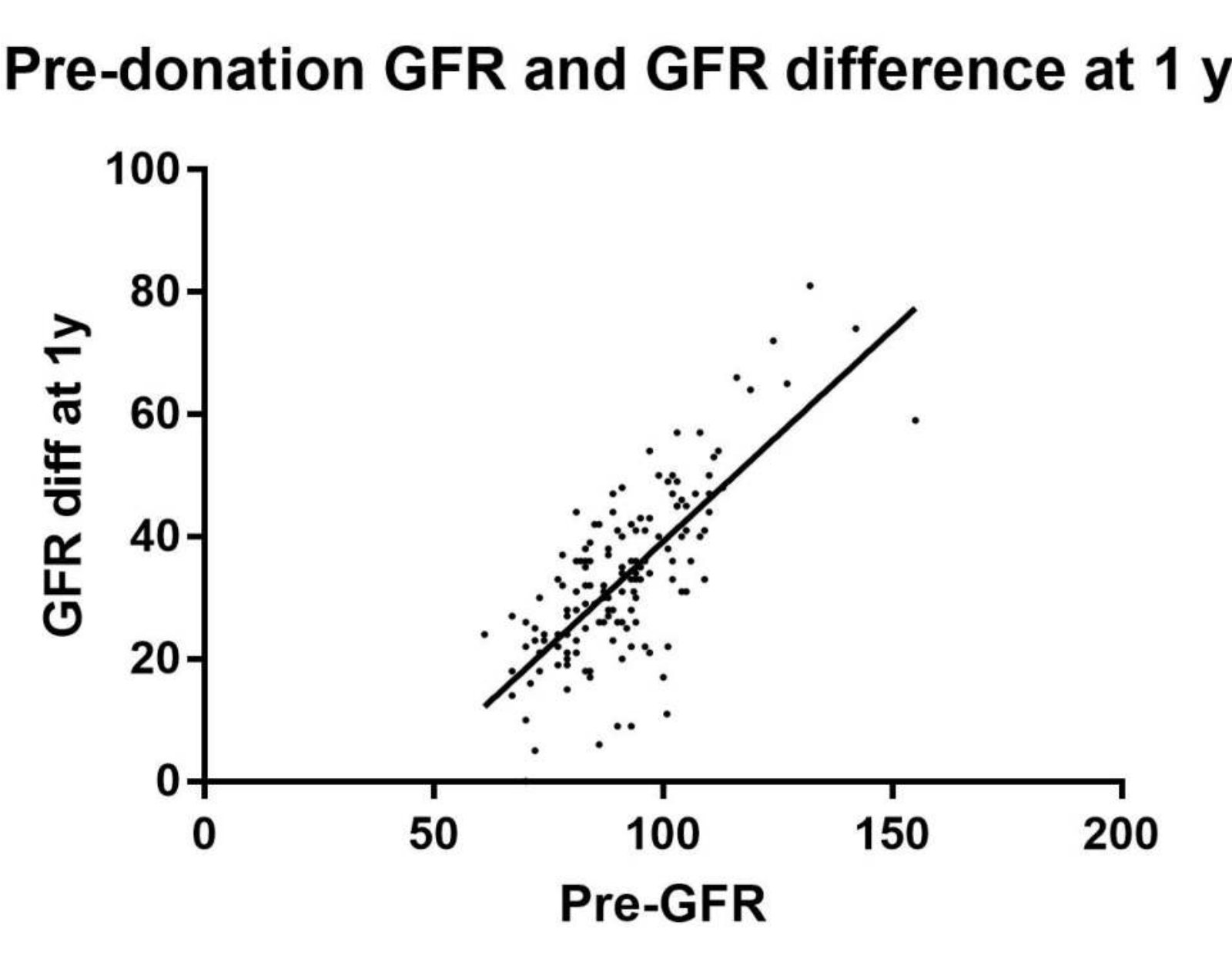

The absolute drop in estimated GFR at 1 year after donation, from pre-donation levels positively correlated with the magnitude of pre-donation calculated GFR, $p=<0.0001^{* * * *}$ $r=0.6649$

Pre-donation GFR and GFR difference at 2 year

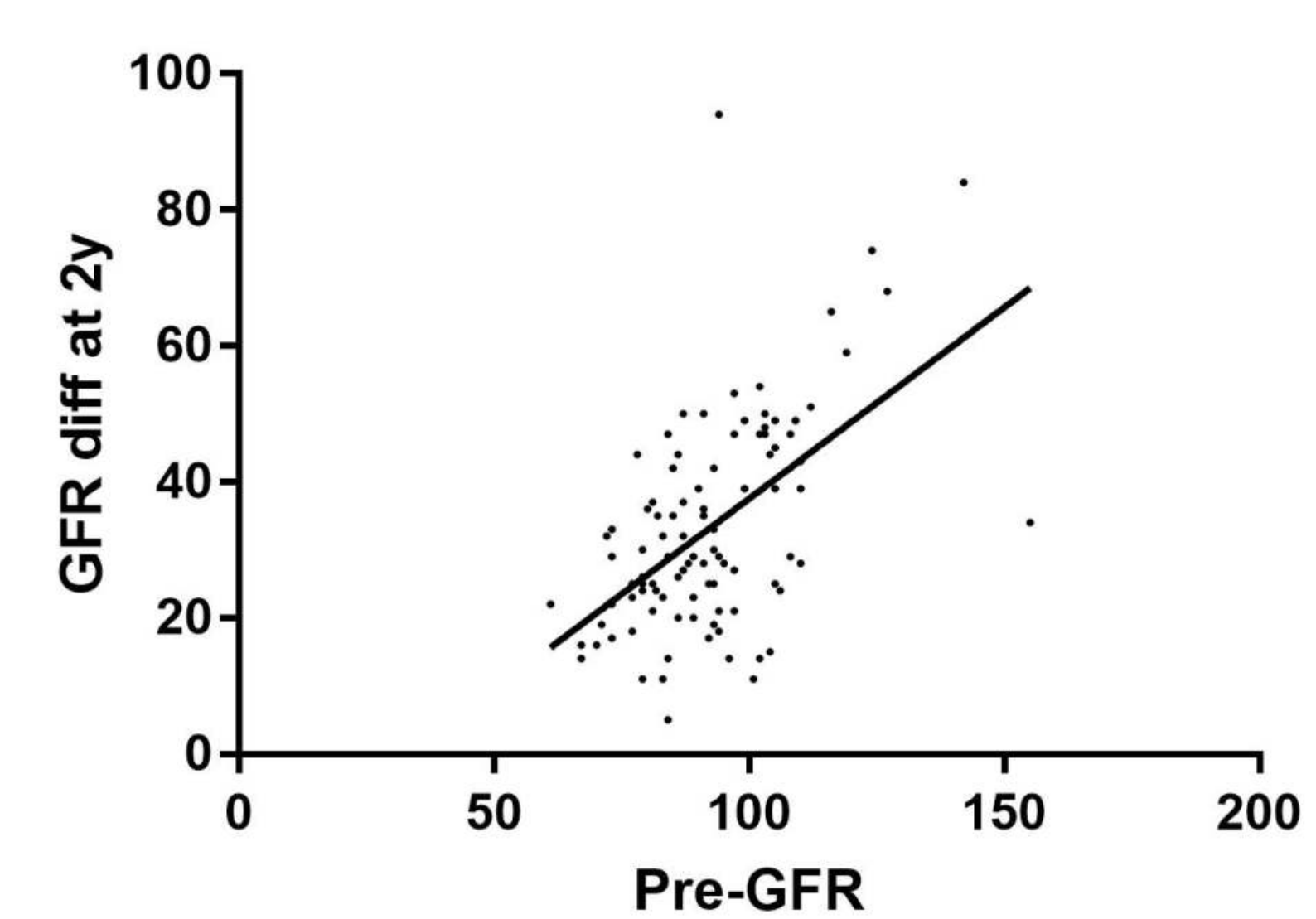

The absolute drop in estimated GFR at 2 years after donation, from pre-donation levels, positively correlated with the magnitude of pre-donation calculated GFR, $\mathrm{p}=<0.0001^{* * * *} \mathrm{R}=0.4951$

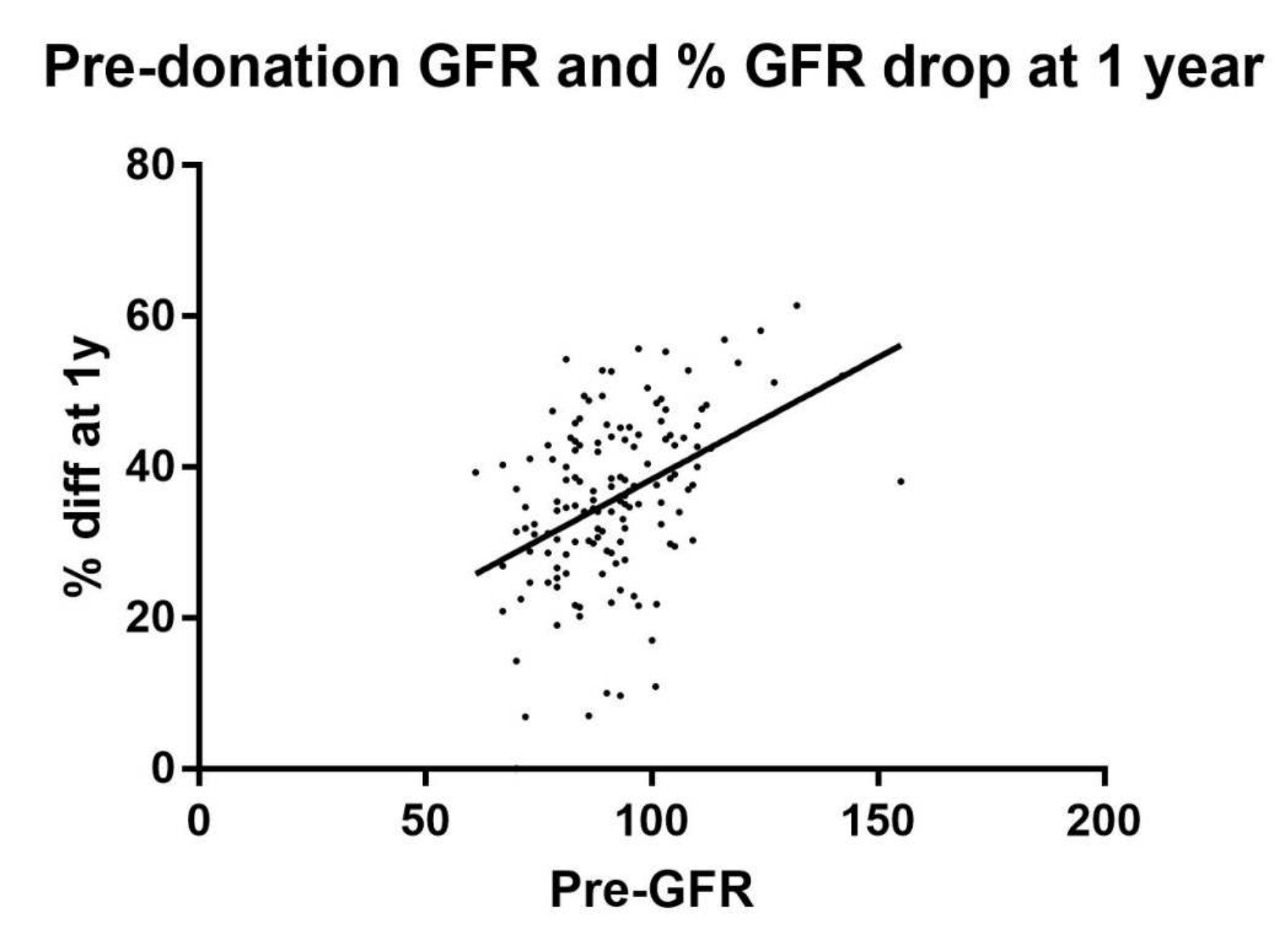

The percentage drop in estimated GFR at 1 year after donation, from pre-donation levels positively correlated with the magnitude of pre-donation calculated GFR, $p=<0.0001^{\star * * *} \mathrm{R}=0.3966$

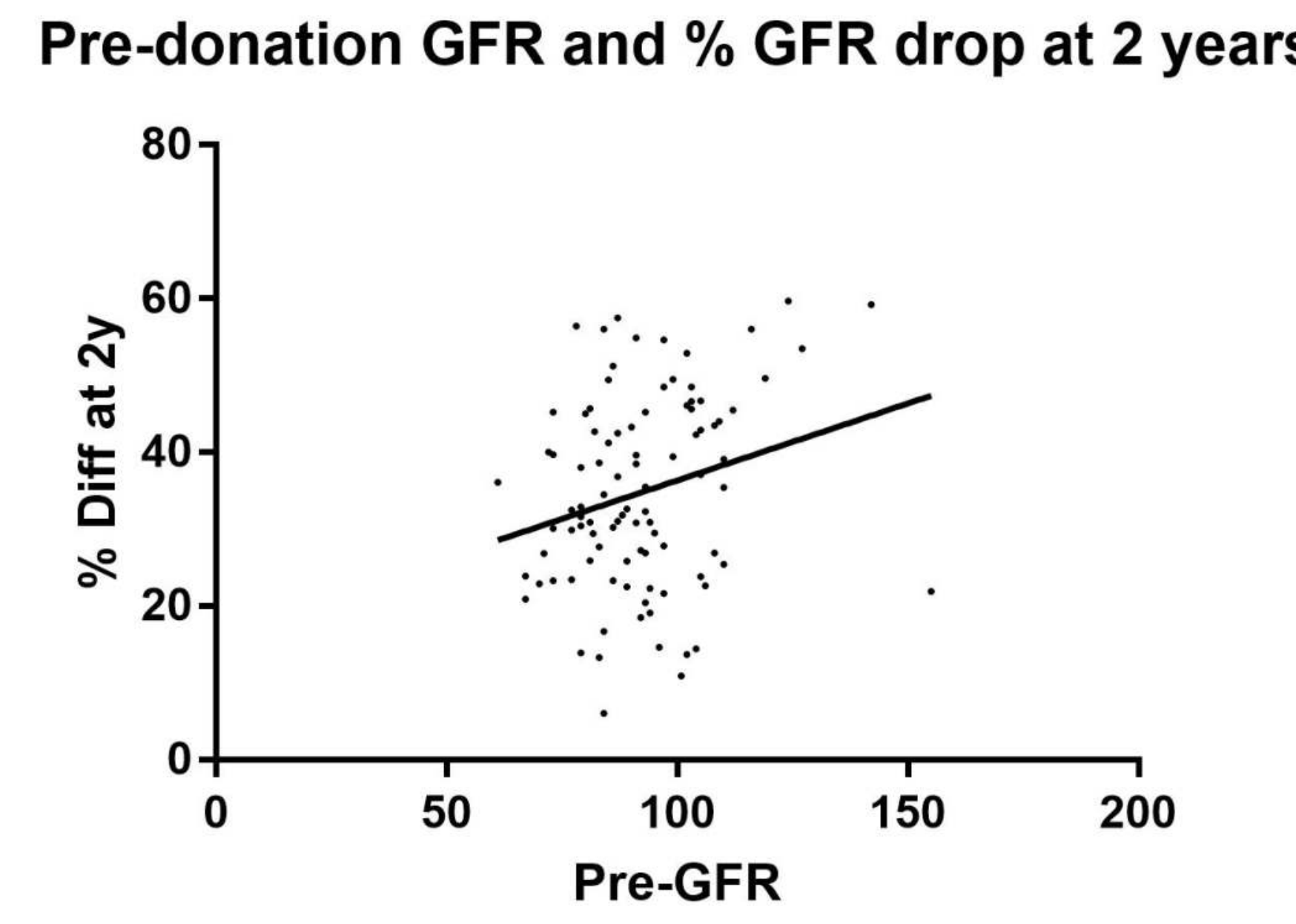

The percentage drop in estimated GFR at 2 years after donation, from pre-donation levels, positively correlated with the magnitude of pre-donation calculated GFR, $p=0.0318^{*} \mathrm{R}=0.2171$

\section{Discussion}

Living kidney donors with higher pre-donation GFR have a greater percentage decline in renal function at 1 and 2 year follow up in this single centre study.

This suggests that there is a compensatory mechanism that occurs in donors with lower initial renal functional capacity.

Is there there an increased risk of developing end stage renal failure (ESRF).?

One study following 50000 living donors for an average of 9.8 years found a low overall ESRF rate of 0.134 per 1000 years at risk. ${ }^{2}$

Another study found no correlation of the ratio of the estimated to the predicted GFR from the time since donation. This suggests that there is no accelerated loss of renal

function after donation when compared to normal ageing. ${ }^{3}$

It would be interesting to investigate further the physiological mechanisms of the decline in function.

\section{References}

1.United Kingdom Guidelines for Living Donor Kidney Transplantation, Compiled by a Joint Working Party of the British Transplantation Society and the Renal Association, Third Edition, May 2011. 2.Cherikh, W. S., Young, C. J., Kramer, B. F., Taranto, S. E., Randall, H. B. and Fan, P.-Y. (2011), Ethnic and Gender Related Differences in the Risk of End-Stage Renal Disease After Living Kidney Donation. Am J Transplant, 11: 1650-1655.

3.Fehrman-Ekholm, I., Dunér, F., Brink, B., Tydén, G. and Elinder, C. (2001). No evidence of accelerated loss of kidney function in living kidney donors: results from a cross-sectional follow-up. Transplantation, 72(3): 444-449. 